\title{
Free family planning services
}

\author{
Lindsay Edouard, MSc, FFPHM, FRCOG, MFFP \\ Overseas Adviser, Journal of Family Planning and Reproductive Health Care
}

The reorganisation of the National Health Service in Britain in April 1974 led to free family planning services. ${ }^{1}$ A few decades before, family planning clinics were run on a voluntary basis and as their doctors were not remunerated, "patients whose husbands earned more than $£ 500$ a year were not advised in clinics but were tactfully referred to the clinic doctor to be seen privately'.2

With its clinics transferred to the newly formed area health authorities, the Family Planning Association decreased its clinical role substantially around 1975 . Negotiations by family planning doctors were more typical of a movement than a mere professional association. Its chairman described the experience as being 'extremely arduous, exceedingly exasperating and absolutely fascinating' whilst she perceived herself as 'more appropriately rebellious in the ranks than pompous on the platform'. 3

Before 1974, some enthusiastic medical officers of health had promoted collaboration with general practitioners (GPs) for family planning by introducing flexible arrangements, such as referrals to dedicated clinics and the waiving of prescription charges by pharmacists. ${ }^{4}$ Family planning clinic doctors were employed on a sessional basis and the national introduction of item-of-service payments ${ }^{1}$ for family planning procedures by hospital doctors and GPs led to certain reservations: extra costs, bias in advice for selection of method, poor quality of care provided by junior doctors without previous training, and duplication through multiple visits by the same individual to $\mathrm{GP}$, hospital and family planning clinic..$^{5-7}$ With the new arrangements, it was anticipated that contraceptive services would move away from the 'Fit it at the end of surgery' approach in general practice. ${ }^{8}$

Free services led to increased attendance by young people. ${ }^{4}$ Furthermore, the 'right to contraception under plain cover' was discussed besides the added value of over-the-counter sales in the context of free supplies from clinics. ${ }^{9}$ Unfortunately, limited financial resources led to reduced family planning services in some regions and gave rise to the comment that 'bearing in mind the cost-effectiveness of family planning, this is a tragedy'.5 The lesson learned applies to the current implementation of health sector reform in various countries whereby essential components of reproductive health services should be provided without user fees.

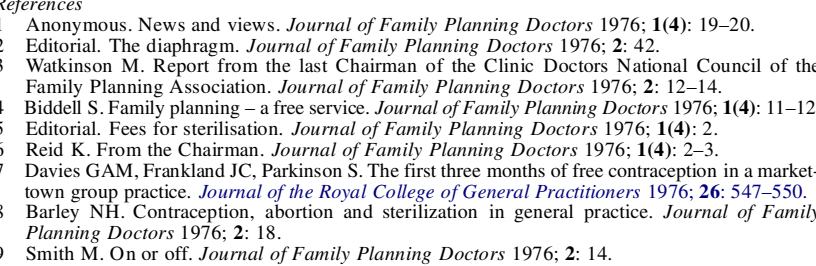

